\title{
RECORTES DA PRISÃO: UM MOSAICO DE EXPERIÊNCIAS LITERÁRIAS NAS PRISÕES FEDERAIS BRASILEIRAS*
}

\author{
PRISON CUTTINGS: A MOSAIC OF LITERARY EXPERIENCES IN \\ BRAZILIAN FEDERAL PRISONS*
}

\author{
Maria Luzineide P. da Costa RIBEIRO**
}

\begin{abstract}
Resumo: Este artigo propõe-se a reunir recortes da prática literária na prisão, por meio de relatos e depoimentos de leitores encarcerados, que corporificam e legitimam, à luz de teóricos importantes da Estética da Recepção, a prática da leitura na prisão como atividade emancipadora. Aqui, interessa-nos a figura desse leitor, seu comportamento e os impactos da sua prática de leitura, sobretudo considerando a política pública de remição de pena pela leitura instituída pela Portaria Conjunta $n^{\circ} 276 / 2012$, do Ministério da Justiça e do Departamento Penitenciário Nacional. Trata-se de recortes de relatos e depoimentos produzidos por presos das Penitenciárias Federais de Campo Grande (MS) e Catanduvas (PR), em Regime Disciplinar Diferenciado (RDD), entre os anos de 2010 e 2013, no âmbito de pesquisa de doutoramento. Os resultados reforçam a relevância da leitura no cárcere para além da ideia de remição de pena.
\end{abstract}

Palavras-chave: Recepção-literária. Remição de pena. Confinamento extremo. Regime Disciplinar Diferenciado. Liberdade.

\begin{abstract}
This paper presents the analysis of clippings of literary practice in prisons through reports and testimonies collected from incarcerated readers, who embody and legitimize the practice of reading in prison. A practice that can be seen as an emancipatory activity from important Reception Aesthetics theorists' points of view. The paper presents this reader's profile, his behaviors as well as the effects of his reading practice, especially considering the public policy of remission through reading carried out by the Ministry of Justice and the Brazilian Penitentiary Department (Joint Ordinance No. 276/2012). The clippings were collected at Federal Penitentiaries of Campo Grande (MS) and Catanduvas (PR), under Differentiated Discipline (RDD), between 2010 and 2013. Results reinforce the relevance of reading in prison, beyond the idea of penalty remission.
\end{abstract}

Keywords: Literary reception. Remission of penalty. Extreme confinement. Differentiated Disciplinary Regime. Freedom.

Na imundície do pátio...

\author{
Vi ontem um bicho na imundice do pátio \\ Catando comida entre os detritos. \\ Quando achava alguma coisa, \\ Não examinava nem cheirava: \\ Engolia com voracidade.
}

\footnotetext{
* Artigo baseado em pesquisa em nível de Doutorado realizada pela autora, iniciada em 2012, e que teve como resultado a tese: Uma teia de relações: o livro, a leitura e a prisão - um estudo sobre a remição de pena pela leitura em Penitenciárias Federais Brasileiras. Este artigo é um recorte dos estudos realizados nesse período e, também, sobre o perfil do leitor do Regime Disciplinar Diferenciado (RDD) e a recepção da obra Crime e Castigo, de Fiódor Dostoiévski, no âmbito do projeto Remição pela Leitura.

** Professora da Secretaria de Estado de Educação do DF (SEEDF). Doutorado em Teoria Literária e Literaturas pela Universidade de Brasília. E-mail: marialuzineide@gmail.com.
} 
O bicho não era um cão, não era um gato, não era um rato.

O bicho, теи Deus, era um homem.

(Manuel Bandeira)

Falar da prisão é também falar da violência humana, de seus conflitos e, sobretudo, da tentativa de controle de todo o seu potencial destrutivo. Ao longo da história, vimos a face cruel da humanidade. Somos conhecidos como os únicos animais que matam seus semelhantes por prazer ou orgulho. Em razão disso, apesar da falência do sistema penitenciário, talvez seja forte a defesa dos sistemas de punição como mecanismos necessários para autodomesticação humana e meios indispensáveis à manutenção da paz (ZALUAR, 2004).

O surgimento da prisão marcou um momento crucial na história da justiça penal por apontar, para além dos “espetáculos” de tortura explícita de outrora, uma direção aparentemente menos violenta e mais igualitária que prometia subtrair do condenado apenas o seu tempo. Desse modo, sob o véu da justiça, os castigos passaram a ser contabilizados em dias, meses, anos, estabelecendo as necessárias equivalências quantitativas entre os crimes e a duração das penas (FOUCAULT, 1997). Seria, por assim dizer, o fim da barbárie.

Entretanto, a promessa de uma sociedade mais justa e igualitária deu lugar à criminalização dos pobres e a modelos de gestão penitenciária que não evoluíram e tornaram evidente a sua falência. Com uma superpopulação prisional de mais de 700.000 pessoas, o sistema penal brasileiro agoniza, subsistindo em condições completamente precárias e extremamente desumanas. Embora contemos com uma legislação consolidada, que, a meu ver, mais promete do que assegura os direitos fundamentais dos apenados, o que se percebe é uma política penitenciária que caminha em direção a uma cultura pró-encarceramento (CHIES, 2013).

Por tudo isso, não podemos esquecer que a prisão provoca mudanças emblemáticas e viscerais na relação do sujeito com o mundo e consigo próprio. Na literatura, a experiência limite vivenciada por Graciliano Ramos no cárcere eclode no interior da obra Memórias do Cárcere. Em sua narrativa, observa-se um indivíduo esvaziado de sua essência à medida que a experiência do confinamento se torna parte de sua vida. Graciliano Ramos foi preso em três de março de 1936, sem nenhuma explicação formal sobre os motivos reais de sua detenção, e permaneceu sem sabê-los até o dia de sua libertação, em 13 de janeiro de 1937. Ficou dez meses sob custódia do Estado durante o governo de Getúlio Vargas. Arbitrariamente, foi preso em Alagoas e enviado a Recife; no porão do navio Manaus, seguiu para o Rio de Janeiro. Graciliano explode: "Não sou um rato, não quero ser um rato" (RAMOS, 1998, p. 23). A degradação no espaço da prisão leva o homem a um processo de animalização. À luz da irracionalidade e da 
violência, o mundo da prisão vai sendo descortinado por Graciliano, de forma direta, por meio de seu relato e da sua impotência diante dos fatos (RIBEIRO, 2012).

Ora, se pensarmos no propósito da prisão de ressocializar o indivíduo, o encarceramento caminha em direção contrária, uma vez que, no cárcere, o preso é tratado, muitas vezes, como mais um "bicho", em referência à epígrafe de Manuel Bandeira. E é essa condição periférica que provoca um rompimento temporal, familiar, e, por conseguinte, faz com que o indivíduo desfaça os últimos laços com seu passado, com sua identidade social, desconectando-se da realidade. Seu apagamento social anula qualquer projeção de futuro. Por isso, o indivíduo preso sempre carrega consigo este sentimento de estar atado a uma condição de presente perpétuo (MASSI; NAKAGOME, 2015).

Contudo, não podemos esquecer que o encarceramento não é uma via de mão única, tem seus efeitos colaterais sobre o preso, e, em longo prazo, também à sociedade. Nessa direção, valho-me da socióloga brasileira Julita Lemgruber (2015), que é enfática quando diz que é hipócrita se afirmar que tão somente a privação de liberdade seja garantia de um "aprendizado de vida em liberdade". Nessa perspectiva, seria necessário o acesso a políticas públicas de educação e de trabalho como elementos basilares à ressocialização do apenado, como exercício diário de autonomia e desenvolvimento pessoal. Nesse cenário, a autora propõe uma discussão importante e sinaliza a necessidade do debate sobre a transformação de criminosos em não criminosos, diante de uma política de repressão, militarização e destituição de direitos fundamentais.

Em um cenário que, por sua natureza, é inóspito e avesso ao exercício de políticas públicas, como seria possível, então, cumprir a proposta brasileira de encarceramento que tem como premissa o "melhoramento" desse sujeito? A legislação penal brasileira prevê que, após o cumprimento da pena, o preso será reinserido socialmente, a partir da progressão temporal de regimes, com vistas a uma execução de pena humanizada e "harmônica", garantidos os direitos constitucionais que objetivam "prevenir o crime e orientar o retorno à convivência em sociedade" (BRASIL, 1984.

Com efeito, não se pode pensar a ressocialização, a partir, simplesmente, do cumprimento da pena; é imprescindível oferecer condições mínimas para que ela seja alcançada (BARATTA, 1990). Acredito que deveríamos caminhar rumo a uma política de "menos cárcere", e não de "uma prisão melhor"; contudo, a sociedade moderna legitima a prisão como experiência indispensável à manutenção da paz. 
Nessa perspectiva, a experiência literária na prisão representa um intervalo na rotina institucional de disciplina e de controle. Nesse sentido, a leitura, aqui, é compreendida como um momento de autossuspensão do sujeito, já que é no ato da leitura que, de certa maneira, é permitido a este leitor transitar entre o mundo real da prisão e o mundo imaginário do texto. É fato, e todos nós sabemos, que o indivíduo, quando encarcerado, necessita respirar outras realidades.

Ao longo de uma década, esta pesquisadora tem envidado esforços no sentido de acessar tal público, verificar tais práticas, promovendo estudos acadêmicos em nível de Mestrado e de Doutorado. Mas, foram os anos, aproximadamente 14, como professora de Língua Portuguesa nas unidades prisionais do Distrito Federal que me ensinaram que o confinamento produz novos leitores e, em alguns casos, comunidades leitoras que compartilham seus gostos, preferências, seus livros, para além dos momentos de aula, como uma necessidade humana, como afirmava Cândido (2006). Na prisão, essa necessidade é potencializada pela vontade de estar ausente, distante, sozinho. Estudos e pesquisas acadêmicas, tais como as desenvolvidas por Martha (2015) e John (2004), já lançam luz sobre essa temática.

A prisão é um lugar com muitas portas fechadas. Atrevo-me a abrir aqui uma das portas que há muito chamou a minha atenção. Caminhando por corredores longos, gradeados e escuros, às vezes, em um silêncio torturante, por outras, nem tanto, pude olhar mais de perto e entrar por uma porta entreaberta: a da leitura. Desde, então, ouso dizer que jamais a fechei.

Embora represente parte de um estudo intenso e longo como o doutoramento, este artigo pretende dar voz a personagens que fazem parte do imaginário social restrito a prisões e apresentá-los como leitores que também podem apreciar um bom livro. Não se pretende aqui tratar seus crimes ou mesmo emitir juízo de valor sobre a justa medida da pena imposta, mas falar do quanto a prática literária vem invadindo as prisões, não com uma ideia ingênua de salvação para todos os males praticados, mas como processo, também, humanizador.

Este artigo propõe-se a reunir recortes da prática literária na prisão, por meio de relatos e depoimentos de leitores encarcerados, que corporificam e legitimam à luz de teóricos importantes da Estética da Recepção, a prática da leitura na prisão como atividade emancipadora. Aqui, interessa-nos a figura desse leitor, seu comportamento e os impactos da sua prática de leitura, sobretudo, considerando a política pública de remição de pena pela leitura instituída pela Portaria Conjunta $n^{\circ}$ 276/2012 do Ministério da Justiça e do Departamento Penitenciário Nacional. São recortes de relatos e depoimentos produzidos por presos das Penitenciárias Federais de Campo Grande (MS) e Catanduvas (PR), em Regime Disciplinar 
Diferenciado RDD), entre os anos de 2010 a 2013, por ocasião de pesquisa, em nível de doutoramento, que reforçam a relevância da leitura no cárcere para além da ideia de remição de pena.

\section{Na prisão, a imaginação também é liberdade}

Uma experiência particular, um colocar-se em estado de perda, de desconforto, capaz de abalar convicções históricas, psicológicas, valores: é essa a descrição feita por Barthes (1983) sobre o ato da leitura. Algo capaz de mover o leitor, ao ponto de colocá-lo em crise, condição sine qua non para que seja libertado pelo imaginário e de tudo aquilo que o prende a uma realidade de vida, muitas vezes, constrangedora. Nesse sentido, uma narrativa da experiência literária de um jovem leitor reverbera esse estado:

O rapaz jovem, de apenas 24 anos, preso há quatro, não quer falar sobre o crime cometido. Diz sentir muita vergonha por não entender como agiu com tanta violência, fazendo mal às pessoas. Mas, quando o tema é a literatura, seu olhar ganha brilho. Confessa que antes de ser preso não tinha o hábito de ler, lera com frequência até os 12 anos, e mais tarde preferira a companhia dos amigos. Hoje, no entanto, com tempo e sem amigos, afirma que a leitura o envolve de tal maneira que não percebe o tempo passar e diz que agora entende que não conhecia o mundo, mas, não pode deixar de falar que, com a leitura, consegue algo tão sonhado: sair da prisão. (Entrevista concedida por um jovem leitor preso na Penitenciária do DF I, em 2012, como parte de pesquisa de Mestrado $^{1}$ ).

Sartre, em sua obra $O$ imaginário (1996), mostra que a consciência imaginante conduz o leitor a uma sensação dupla de liberdade e de criatividade. Contudo, reforça que, para que isso ocorra, é necessária a aniquilação do mundo do sujeito, pois, só assim, será dada a ele a possibilidade de criação de um mundo novo em substituição ao primeiro. $\mathrm{O}$ autor destaca que a consciência imaginante pode modificar o mundo para a consciência, possibilitando o surgimento dos objetos que são imaginados. Como se ocorresse uma fusão entre o mundo do leitor e o mundo imaginado.

Para Sartre, o ato de imaginação é um ato mágico. É neste processo de encantamento que surge, diante dos nossos olhos, o objeto desejado. No entanto, declara o pensador francês, os objetos de nossas consciências imaginantes se assemelham a silhuetas criadas na infância,

\footnotetext{
${ }^{1}$ Trata-se da pesquisa de Mestrado da autora que teve como resultado a dissertação $O$ mundo como prisão e a prisão no mundo: Graciliano Ramos e a formação do leitor em presídios do Distrito Federal, e era constituída por entrevistas, oficinas literárias e rodas de conversas com presos e presas do Sistema Penitenciário do DF. Foram entrevistadas 200 pessoas com o objetivo de compreender a formação desse leitor. Esse depoimento faz parte do acervo de entrevistas concedidas durante esse período. O relato é de um jovem leitor que foi estudante da unidade escolar e, posteriormente, trabalhou internamente na escola. Em 2012, aguardava a progressão para o regime prisional aberto.
} 
quando nos é apresentado um rosto sem perfil, mas com dois olhos bem desenhados, imagens consideradas, muitas vezes, irreais e que exigem de nós, sobretudo, uma ingenuidade no olhar para serem captadas de diferentes perspectivas e momentos. Mesmo que pareçam ausentes, é fato, tais objetos estão presentificados por meio de nossa imaginação. Enfim, para tocá-lo ou mudá-lo e para agir sobre tais objetos, o autor afirma, é necessário que também me torne irreal, que me envolva de tal maneira, que viaje pelas páginas do livro e me ausente da realidade (SARTRE, 1996).

Em um mundo imaginário, diz Sartre (1996), não há sonhos de possibilidades, já que as possibilidades pressupõem um mundo real e, com ele, possibilidades pensadas. Neste aspecto, não há como haver um recuo da consciência em favor de uma história possível a se contar dentro de uma logicidade. Logo, para estar em um mundo imaginário, enfatiza o autor, é condição sine qua non que a consciência seja também imaginária.

Em convergência com as ideias de Sartre (1996), Jauss (1979) afirma que a leitura, como experiência estética, resulta sempre tanto libertação de alguma coisa, quanto libertação para alguma coisa. Se por um lado, a leitura permite ao leitor desprender-se das incongruências de uma vida real; por outro, ao se deslocar para o universo textual, o leitor renova sua percepção do mundo. Neste novo contexto, o leitor tem a impressão de escapar de si próprio, ao mesmo tempo em que se abre também para uma experiência de alteridade. Ler, portanto, torna-se uma viagem.

Percebemos a confluência destas ideias na obra A leitura, de Vincent Jouve (2002), na qual o ato da leitura é compreendido como uma entrada insólita em outra dimensão que, na maioria das vezes, enriquece a experiência e permite ao leitor, em um primeiro momento, escapar desta realidade para o universo da ficção e, em um segundo momento, de maneira ainda mais surpreendente, voltar ao real, nutrido do fictício. É neste vaivém que o autor esclarece a questão: ao ler um romance, por exemplo, aceitamos esquecer por um tempo a realidade que nos cerca para nos ligarmos novamente com a vida da infância, na qual histórias e lendas eram tão presentes. Ao acordar o eu imaginário, normalmente adormecido no adulto acordado, a leitura nos leva de volta ao passado (JOUVE, 2002). Percebemos, assim, que o imaginário de cada leitor tem um papel tão relevante na representação, que poderíamos quase falar de uma presença da personagem no interior deste leitor. E essa sensação de consubstancialidade entre o sujeito que lê e a personagem representada não poderia jamais ser dada sob nenhuma ótica, que não esta agora citada, de trânsito desse leitor promovida pelo imaginário. 
Neste sentido, o impacto da leitura na existência do sujeito é mais real do que se imagina. É de fato a significação da obra definida como a passagem do texto para a realidade que faz da leitura uma experiência concreta, uma vez que tal experiência pode ser emancipatória e mundivivencial, permitindo ao leitor a reorganização de sua visão de mundo.

$\mathrm{O}$ ato de ler na prisão representa a possibilidade de o leitor atingir o ápice desta leitura, não apenas de maneira funcional, mas de maneira profunda, em uma experiência subjetiva e instigante. Esta singularidade, segundo Compagnon (2001), permite ao leitor se aproximar de verdades que o rodeiam e de possíveis questionamentos produzidos a partir desta nova consciência da realidade. Logo, levando-se em conta a disciplina moduladora e extremamente desumana proposta pelo sistema penal, a literatura subverte toda e qualquer ideia de alienação, dando ao leitor a possibilidade de repensar a sua existência.

\section{Conhecendo os leitores}

Poderíamos considerar um território particular, dentro do universo caótico das prisões brasileiras, as penitenciárias localizadas no Paraná, Mato Grosso do Sul, Roraima, Rio Grande do Norte e, mais recentemente, a unidade inaugurada em Brasília, já que apresentam celas individuais, sem problemas de superlotação e com um eficiente sistema de segurança. Não fossem as limitações para a efetiva execução de políticas públicas de ressocialização, poderíamos dizer que são espaços perfeitamente alinhados ao cumprimento da Lei de Execução Penal (BRASIL, 1984).

Com uma proposta disciplinar diferenciada, as Penitenciárias Federais têm por objetivo retirar os líderes de organizações criminosas de suas prisões locais para evitar a falência completa do Sistema Penitenciário. No cenário nacional, tais lideranças são conhecidas por arregimentar pequenos exércitos no interior das prisões. Com fulcro na neutralização e no afastamento de tais indivíduos, por tempo, muitas vezes, indeterminado, nesses espaços, observa-se o confinamento extremo, que tem como principal preocupação a contenção e o monitoramento do criminoso.

Com base nos dados fornecidos pelo DEPEN/MJ, no I anuário do Sistema Penitenciário Federal em 2015, foi possível traçar um perfil dos presos federais, a partir dos questionamentos descritos no referido documento, uma vez que é muito difícil acessar tais indivíduos em razão da característica do público e em virtude do rígido modelo de segurança. O Sistema Penitenciário Federal (SPF) contava com 430 internos. Nesse contexto, foram respondidos 
85,35\% dos questionários pelos apenados, de forma anônima e voluntária, sendo analisados os questionários de 367 internos (BRASIL, 2015).

De forma sintetizada, o I anuário descreve um perfil de público bem diferente da população carcerária nacional, com presos considerados mais velhos, que apresentam maior faixa etária, com relacionamentos estáveis, na sua maioria, e contrariando as expectativas, com uma infância que pode ser considerada feliz (70\%), sem grandes experiências traumáticas, tendo seu ingresso ainda jovem no mundo do crime (BRASIL, 2015).

Nesse aspecto, a idade da prática do primeiro delito, para 39,58\%, ocorreu entre $\mathbf{1 8}$ e 24 anos, já para 37,85\%, tal fato ocorreu quando tinham entre 13 e 17 anos. Ainda na primeira infância, 4,51\% dizem ter cometido o primeiro delito com menos de 12 anos. Entre 25 e 29 anos, $12,15 \%$ responderam ser esta a idade relativa ao primeiro delito. Apenas 3,82\% afirmaram ter ocorrido entre os 30 e 40 anos. Após os 40 anos, somente 2,08\% admitiram tal prática (Cf. Gráfico 1).

Gráfico 1 - Idade do Primeiro Delito

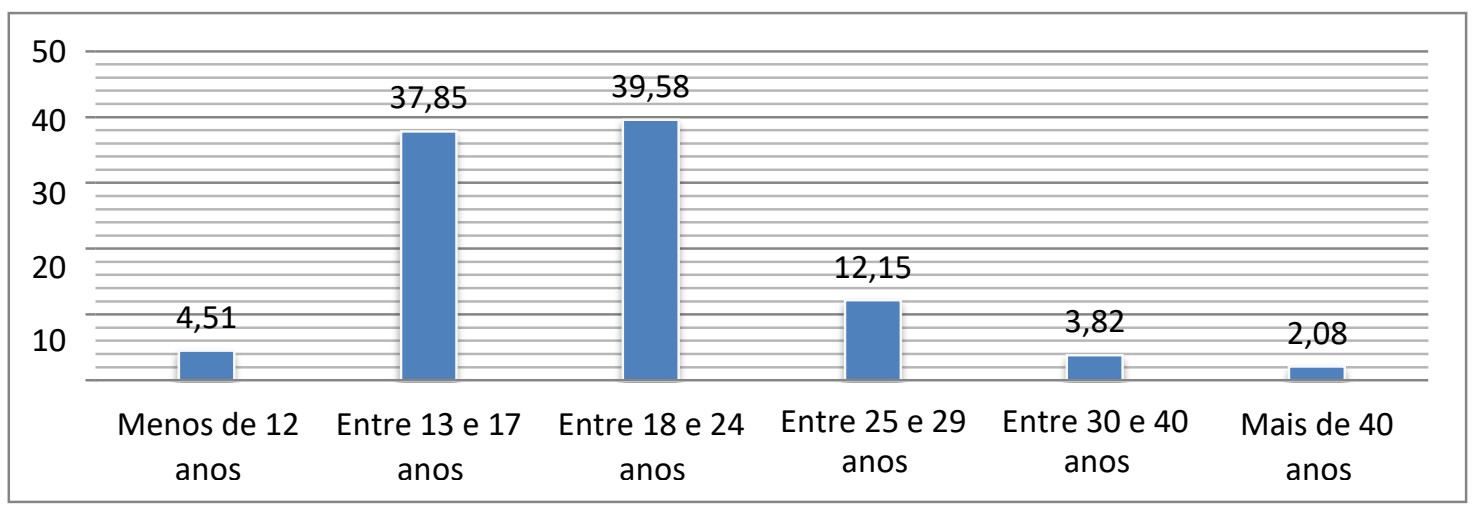

Fonte: DEPEN/MJ -2015.

Composto por uma população mais velha, como anteriormente mencionado, o SPF apresenta no aspecto faixa etária uma população de idade média mais elevada. Enquanto no SPF, 41,34\% dos presos têm entre 35 e 45 anos, fase considerada de maior maturidade; no Sistema Prisional Estadual (SPE), a porcentagem de jovens (18 a 29 anos) é bem maior, em torno de 56\%. Ainda se percebeu no SPF a presença de pessoas mais velhas, entre 46 e 60 anos $(12,01 \%)$, bem distante dos 7\% representantes desta faixa etária no SPC (Cf. tabela 1, abaixo). 
Tabela 1 - Faixa etária dos presos do Sistema Prisional Estadual e do Sistema Penitenciário Federal (em percentagem)

\begin{tabular}{lcc} 
Faixa etária & SPF & Sistema Prisional Estadual \\
\hline Acima de 61 anos & 0,56 & 1 \\
46 a 60 anos & 12,01 & 7 \\
35 a 45 anos & 41,34 & 17 \\
30 a 34 anos & 26,54 & 19 \\
25 a 29 anos & 14,80 & 25 \\
18 a 24 anos & 4,75 & 31 \\
\hline
\end{tabular}

Fonte: DEPEN/MJ -2015.

Em relação ao estado civil, o perfil dos presos do SPF é muito diferente das unidades do SPE. Os presos das unidades federais estão, em sua maioria, em situação de união estável $(54,8 \%)$, apenas $22,91 \%$ se dizem casados e apenas $18 \%$ assumiram a condição de solteiros. Em contrapartida, no SPE, a maioria dos presos é solteira (57\%). Apenas 10\% são casados. Em união estável, este número representa 29\% (Cf. tabela 2, abaixo).

Tabela 2 - Estado Civil dos presos no Sistema Prisional Estadual e no Sistema Penitenciário Federal

\begin{tabular}{lcc} 
Estado Civil & SPF & Sistema Prisional Comum \\
\hline União Estável & 54,80 & 29 \\
Casado & 22,91 & 10 \\
Solteiro & 18,27 & 57 \\
Separado & 3,10 & 1 \\
Divorciado & 0 & 1 \\
\hline
\end{tabular}

Fonte: DEPEN/MJ -2015.

O tráfico de entorpecentes aparece como o crime de maior incidência penal também na fase adulta destes apenados. Muitos dos entrevistados relatam não entender a razão de estarem no SPF, se sentindo, por vezes, perseguidos (BRASIL, 2015).

Em junho de 2009, foi iniciado o projeto de Remição pela leitura na Penitenciária Federal de Catanduvas, no Paraná, com a autorização do então Juiz Federal Corregedor Sergio Fernando Moro, que determinou a sua forma de execução e indicou a primeira obra. O livro escolhido foi Crime e Castigo, e sua leitura foi feita por 65 presos. Apesar de ser regulamentado pela Portaria 276/2012, o projeto de Remição pela Leitura não é obrigatório nas penitenciárias federais, atendendo, a priori, ao direito do preso a atividades educacionais complementares. A Remição pela Leitura como uma política pública federal visa, sobretudo, assegurar ao preso de regime fechado a remição de pena por meio de atividades de leitura. 
Para a execução do projeto, nas bibliotecas das Penitenciárias Federais, é necessário que o acervo tenha, no mínimo, 20 exemplares de cada obra a serem trabalhadas. Cada preso participante do Projeto tem um prazo de 21 a 30 dias para a leitura de uma obra e deve, ao final deste período, apresentar uma resenha sobre a obra lida, o que possibilita a remição de 04 dias de sua pena, segundo critério legal de avaliação. Ao final de até 12 obras lidas e avaliadas, o preso tem a oportunidade de remir 48 dias, no prazo de 12 meses.

Cada unidade conta com uma Comissão Pedagógica responsável pelo projeto, composta por servidores das unidades prisionais federais, nomeada pelo Diretor de cada unidade e presidida pelo chefe da Divisão de Reabilitação da referida unidade, com o acompanhamento de um pedagogo, que faz a avaliação das competências a serem alcançadas, relacionadas à compreensão e à compatibilidade do texto produzido com o livro escolhido, sendo observados os princípios de estética (respeito ao parágrafo; não rasurar; respeito à margem; letra cursiva e legível); limitação ao tema (resenhar somente o conteúdo do livro) e fidedignidade (proibição de resenhas que sejam consideradas plágio).

Diante das poucas atividades desenvolvidas, o que se percebeu foi que, no período de 2009 a 2016, o projeto apresentou a adesão de 60\% dos presos, com 7179 participantes. Durante o referido período (2009 a 2016), 6.051 resenhas foram produzidas. Observou-se um baixo índice de evasão do programa, apenas $10 \%$. Do ponto de vista educacional, no SPF, são poucos os internos analfabetos, tendo a maioria cursado o ensino médio.

Segundo relato dos internos, o hábito de leitura não veio com o encarceramento, já fazia parte de suas vidas. Em virtude de hábito ou mesmo do confinamento extremo, quase todos leem, em média, 10 livros ou mais ao ano, mesmo não estando integrados ao programa de Remição de Leitura. Em uma autoavalição, consideram-se bons escritores e leitores assíduos (BRASIL, 2015).

Tabela 3 - Hábito de leitura no Sistema Penitenciário Federal (em percentagem)

Hábito de leitura no SPF

\begin{tabular}{ll}
\hline Leio mais de 10 livros por ano & 80,91 \\
Leio 10 livros por ano & 7,12 \\
Leio 5 livros por ano & 6,15 \\
Leio 1 livro por ano & 3,88 \\
Não leio & 1,94 \\
\hline
\end{tabular}

Fonte: DEPEN/MJ -2015. 
Os gostos literários guardam semelhança com a realidade extramuros, já que, na sua maioria, são de leituras de best-sellers e livros de suspense. As indicações de livros revelaramse muito próximas da realidade extramuros, pautadas no caráter utilitário da leitura e nos interesses por livros que, de certa maneira, são exigidos em exames e vestibulares. Neste regime, é complexo pensar em gosto literário, uma vez que os internos não são questionados quanto a este assunto. Portanto, observa-se uma reprodução dos modos de apropriação de leitura que privilegiam o seu caráter utilitário em detrimento da sua fruição.

Quadro 1 - Obras sugeridas para leitura no projeto de Remição pela Leitura para o ano de 2017 (PFCG)

\begin{tabular}{|l|l|}
\hline \multicolumn{1}{|c|}{ LIVROS } & \multicolumn{1}{c|}{ AUTORES } \\
\hline 1808 & Laurentino Gomes \\
\hline Viva o povo brasileiro & João Ubaldo Ribeiro \\
\hline As esganadas & Jô Soares \\
\hline Quando ela se foi & Harlan Coben \\
\hline Número Zero & Umberto Eco \\
\hline Feliz por nada & Martha Medeiros \\
\hline Fim & Fernanda Torres \\
\hline Inferno & Dan Brow \\
\hline O negociador & John Grisham \\
\hline Depois da escuridão & Sidney Sheldon \\
\hline A vida como ela é & Nelson Rodrigues \\
\hline Feliz Ano Velho & Marcelo Rubem Paiva \\
\hline O morro dos ventos uivantes & Emily Bronte \\
\hline Madame Bovary & Gustave Flaubert \\
\hline
\end{tabular}

Fonte: DEPEN/MJ.

\section{Entre o crime e o castigo: algumas leituras possíveis}

A leitura foi instituída como prática nas Penitenciárias Federais Brasileiras desde o ano de 2012. Surgiu como uma medida de baixo custo e risco à segurança institucional, uma vez que a realização de alguma atividade se mostrava pouco exequível. $\mathrm{O}$ monitoramento e o alto grau de confinamento, atrelados ao ócio, tornavam a espera dos presos pelo término da pena um processo angustiante, se consideradas as 22 horas de completo isolamento em cela individual.

Assim, foi estabelecida a prática de leitura como um mecanismo legal de remição de pena que, como outra atividade qualquer, enfrenta os entraves inerentes aos sistemas de punição. Como em um prolongamento dos direitos do preso, a leitura figura, neste contexto, como um adendo, em alguns casos, à educação formal. Mas, se pensarmos que, em algumas prisões, onde 
a educação inexiste ou mesmo funciona com acesso limitado e de forma precária, como pensar em um processo de formação de leitores?

Pesquisas sobre a leitura dão conta de uma realidade extramuros preocupante quando são avaliados os índices de leitura e interpretação de textos, bem como o processo de fruição vivenciado pelos jovens leitores em formação em nossas escolas. Observa-se que quanto menor a escolaridade, menos leitura e pouco desenvolvimento da habilidade leitora (BRASIL, 2015).

A obra Crime e Castigo é um clássico do século XIX e uma das principais obras da Literatura Russa, escrita pelo renomado autor Fiódor Dostoiévski. Além da história pessoal do autor, que também esteve preso por quatro anos nas prisões da Sibéria, a obra tem como temática a relação do crime, da culpa e da prisão. Foi considerada a obra mais lida nas penitenciárias federais brasileiras.

Possivelmente, esta obra foi escolhida por tratar de temas universais sobre a condição humana. A narrativa traz como pano de fundo um crime de homicídio praticado por um jovem, socialmente angustiado, admirador de Napoleão Bonaparte e que se alimenta da teoria de que grandes homens também poderiam praticar seus crimes, sem grandes arrependimentos. Raskólhnikov, personagem principal, decide matar uma velha agiota e, ocasionalmente, sua irmã, por presenciar o crime. Entre dilemas pessoais, atormentado pela culpa, o personagem segue seu caminho, atravessado por temáticas filosóficas, religiosas e sociais entre a linha tênue do certo e o errado. Sem dúvida, trata-se dos efeitos estéticos e da recepção de uma leitura marcada pela confissão e arrependimento no cometimento de primeiro delito e, de certa forma, pela oportunidade do leitor de reviver tais sentimentos nas palavras de Dostoiévski (DOSTOIEVSKI, 2008).

A análise que aqui se propõe parte de alguns trechos de depoimentos de participantes do projeto Remição pela Leitura do Sistema penitenciário Federal, com o objetivo de entendermos melhor a representação desta leitura como produtora de sentido e prática emancipadora no espaço prisional, a partir do compartilhamento das experiências literárias.

Daremos início pelo texto do preso da cela 41 da Penitenciária de Catanduvas (PFCAT), depoimento registrado no ano de 2010 , no qual o preso agradece pela oportunidade em participar no referido projeto. V.C.S. começa seu depoimento (1) sintetizando o ato da leitura: "Em se tratando de leitura tudo é genial", e continua: "Foi um projeto muito bom, pois mexe com o nosso cortex e com certeza vai enriquecer nossa bagagem de vida, desperta nosso enteresse pela leitura e exercita nossa inteligência (sic)". Para este leitor, a leitura representa a 
possibilidade de ampliação do conhecimento, de construção do intelecto, exercício de criatividade.

Figura 1 - Depoimento 01(Recorte do texto original)

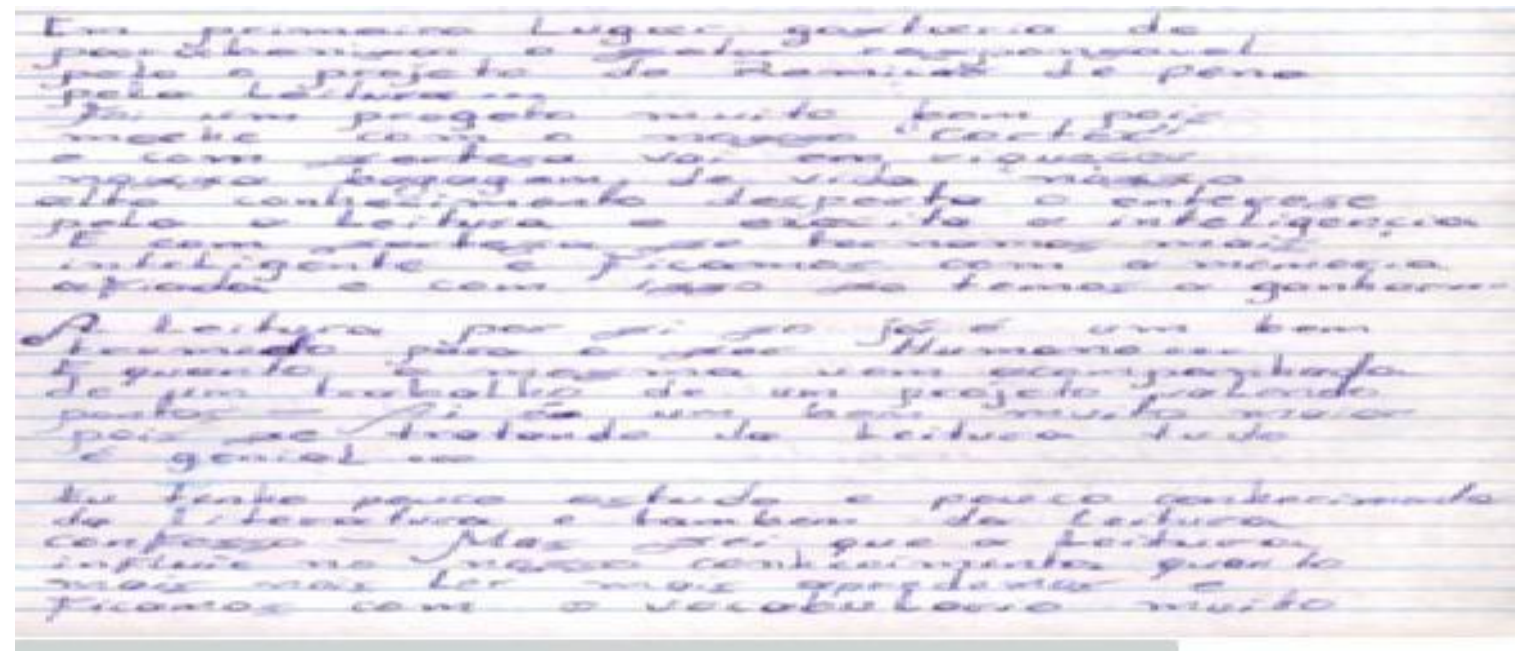

Fonte: DEPEN/MJ.

Ao mesmo tempo em que nos permite, a partir das dificuldades ortográficas apresentadas em seu texto, compreender o seu esforço na utilização de termos mais elaborados como tentativa, talvez, de demonstrar a sua evolução pessoal, V.C.S. enfatiza que fica com "a memória mais afiada" e declara que tem muito a ganhar, reforçando a leitura como ação afirmativa no contexto prisional. Em outro trecho, destaca que a leitura, por si só, já faz um bem tremendo para o ser humano. Confessa que tem pouco estudo e pouco conhecimento da literatura e da leitura, mas se diz esperançoso com o projeto, pois "acredita que a leitura influi no nosso conhecimento quanto mais ler mais aprendemos (sic)".

Outro depoimento (2) marcante é o de W.A.V.M., um dos presos leitores da Penitenciária Federal de Campo Grande (PFCG), registrado no ano de 2012, em que agradece aos idealizadores do projeto e "aos que seguem abraçando este trabalho", ao mesmo tempo em que deixa claro que "nós internos temos tempo demais e atividade de menos". No seu depoimento, o leitor inicia seu relato descrevendo os benefícios do projeto, o ganho de conhecimento com a leitura e a familiarização com a escrita e suas regras e, em um segundo momento, aponta o benefício da remição de pena de 04 dias. Segue dizendo que compreende todos os benefícios da leitura e destaca que é "uma forma de interação", pois os debates sobre os autores e temas a serem analisados, "desvia o foco do mundo do crime". Ao final, revela que 
as notas de suas resenhas são guardadas como um prêmio, justamente por alimentar a sua autoestima (Cf. Figura 2, abaixo).

Figura 2 - Depoimento 02 (Recorte do texto original)

Fonte: DEPEN/MJ.

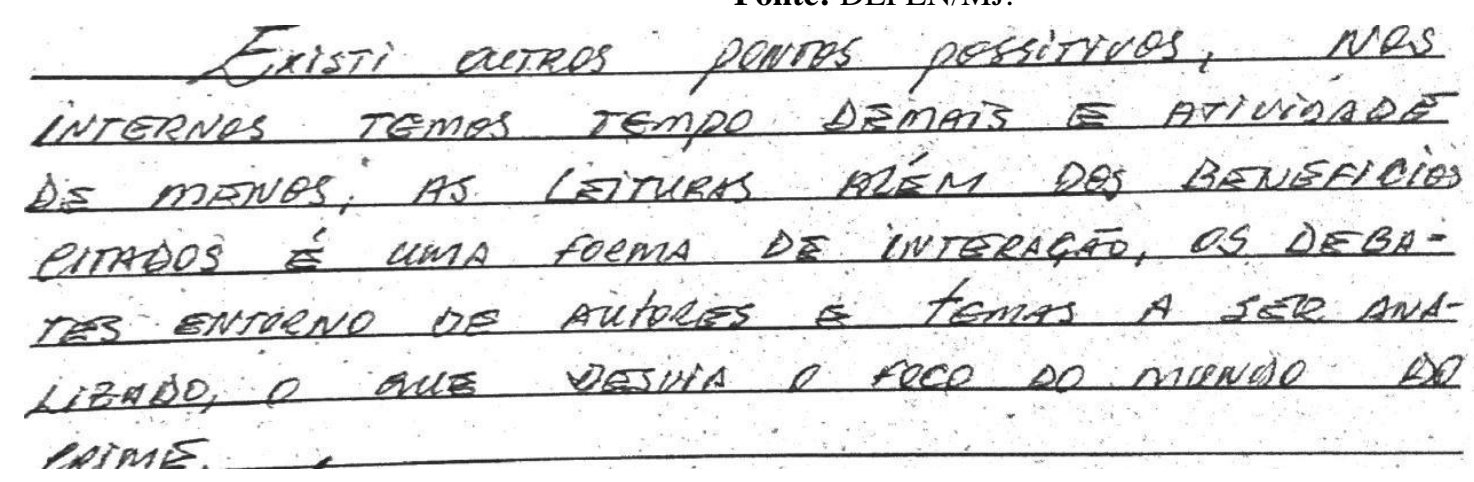

Neste recorte, o leitor estabelece uma relação de gratidão com o projeto desenvolvido, não percebendo ou mesmo não defendendo a ideia, que também seria muito pertinente, de que é um dever do Estado proporcionar a ressocialização por meio de atividades, inclusive educacionais. Coloca em debate as promessas da manutenção dos direitos sociais dos presos frente à cultura do encarceramento, de acordo com o argumento defendido porChies (2013). Menciona, ainda, a sua rotina de ócio com o trecho "atividade de menos, tempo demais", sua solidão por meio da interação promovida pela leitura e, ao final, chama atenção para um aspecto importante da leitura: "desvia o foco da vida do crime", ensejando a existência recorrente de diálogos em torno desta temática que, geralmente, ocorrem nas conversas no pátio, e a leitura de um livro rompe com essa rotina, trazendo novos temas para o banho de sol. Como possível impacto desta leitura, revela-se a possibilidade, para alguns, de ruptura dos paradigmas de reincidência e de retroalimentação da indústria do crime. A leitura configura-se como instrumento de desalienação deste sujeito. Em outra perspectiva, o leitor defende que a leitura abre os horizontes, por meio da imaginação, libertando o indivíduo.

Embora direcionada, não havendo escolha de leitura por parte do leitor, é fato que, ainda assim, encerra em si o seu caráter transformador. O entrevistado reforça, também, como no primeiro depoimento, o aspecto funcional da leitura: o ganho de conhecimento com a leitura e familiarização com a escrita e suas regras. E reforça, em seu depoimento, este novo território afetivo que é estabelecido por meio das notas guardadas que alimentam a autoestima.

Instigante é o depoimento (3) de M.A.K., leitor da Penitenciária Federal de Campo Grande (PFCG), e que, no ano de 2012, reiterou a importância da remição de 04 dias pela 
leitura. Em outras palavras, M.A.K. ressaltou que o projeto foi importante porque incentivou o participante a trabalhar seu intelecto de forma mais elaborada, utilizando seu senso crítico e sua imaginação, o que, segundo ele, na rotina diária da penitenciária federal, não é muito exercitado. Um ponto que merece destaque neste depoimento é o fato de que, para o leitor, o ato de determinar um prazo para leitura significa ter responsabilidade. Descreve tal atitude como compromisso, um aspecto destoante da proposta de desprogramação da vida do indivíduo defendida em instituições totais e que, segundo Erving Goffman (1990), tem como objetivo a alienação do sujeito como via importante à modulação de suas vontades no cotidiano da prisão.

Neste sentido, esta análise de ruptura de rotinas ganha força, ao continuarmos ainda no depoimento (3), no qual o participante, em seu discurso final, lança sua expectativa: "acredito também que, através do trabalho de resenha crítica, seja possível aos examinadores testemunharem o quão alienado possa estar o participante do mundo extramuros", e, assim apresentar, as autoridades competentes propostas para melhor trabalhar a ressocialização deste indivíduo. Ao final do texto, M.A.K, despede-se agradecendo por todas as vezes em que pode participar do projeto.

Figura 3 - Depoimento 03 (Recorte do texto original)

Fonte: DEPEN/MJ.

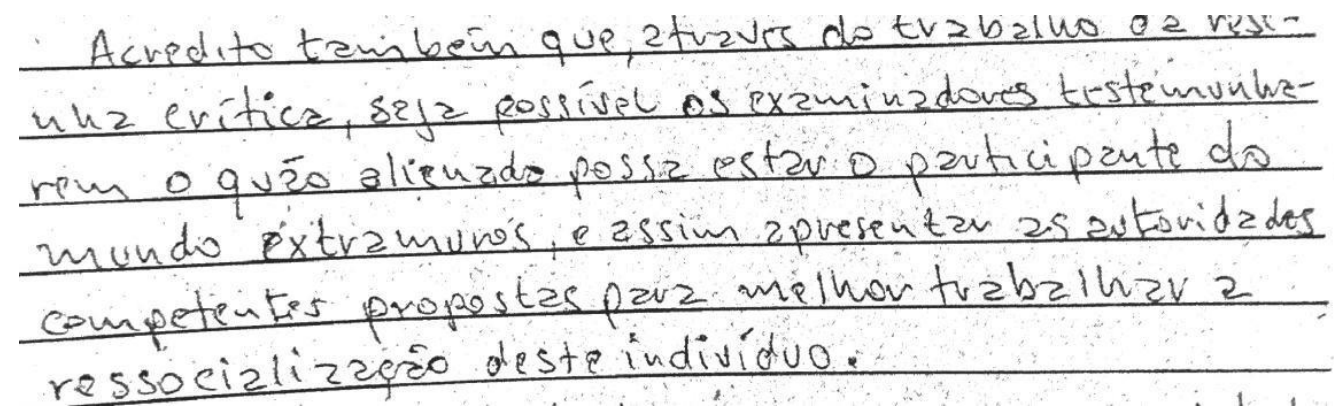

O terceiro depoimento revela um discurso recheado de verdades que permite entrever a remição de pena pela leitura e sua importância, não só no que diz respeito a sua funcionalidade, mas, sobretudo, à possibilidade de exercício do intelecto, tão pouco praticado, e à possibilidade de desalienação das imposições inerentes à fábrica-prisão, à produção de corpos dóceis (FOUCAULT, 1997).

Enfim, o entrevistado termina seu texto, expressando mais uma verdade desgastada nos discursos e evidente nos indicadores oficiais: a ineficiência de políticas públicas de ressocialização (BRASIL, 2015). Por isso, deixa clara a sua esperança de que os examinadores 
também vejam, para além da resenha, as lacunas deixadas pelo processo de encarceramento massivo.

Em outro depoimento, fica claro o poder da leitura sobre a ideia de remição de pena, já que não se pode esquecer a leitura como algo que me dá conhecimento e não somente como simples redutor de pena, de uma antecipação da liberdade. Reflexões promovidas a partir da recepção da leitura de Crime e Castigo, que só foram possíveis conhecer por meio dos depoimentos.

Neste sentido, cabe uma análise crítica do texto. A priori, é complexa a ideia de pedir a um detento que se expresse, dada a situação extrema de controle à qual está submetido; se de um lado ele deseja expor sua opinião, de outro, entende que pode ser extremamente perigoso defendê-la. Talvez, por isso, seja perceptível nos trechos acima que, mesmo com limitações quanto à produção textual, declaradas pelos autores, estes leitores preocupam-se em causar boa impressão ao examinador.

Neste segundo momento, a análise será composta por depoimentos realizados em vídeo e compartilhados durante a pesquisa de doutoramento da autora. Começaremos com uma reportagem realizada na Penitenciária Federal de Catanduvas (PFCAT), em 2013, e cedida pelo DEPEN/MJ. A entrevista foi realizada pelo canal franco-alemão ARTE. Nele, a apresentadora defendia que a liberdade pela leitura é a nova filosofia para desocupar as prisões. Ao apresentar a prisão e essa nova modalidade, in campo, o repórter Marcos Berger descrevia o processo como uma espécie de redenção pela Literatura e afirmava que, de certa forma, o tempo passaria um pouco mais rápido.

Nessa reportagem, foram entrevistados três participantes do projeto de remição pela leitura. Na primeira entrevista, o repórter conversa com C.L., preso condenado a 98 anos de prisão por sequestro e homicídio, que permanecerá encarcerado por, pelo menos, 30 anos, tempo máximo de encarceramento no Brasil, à época da entrevista, conforme preconizava o Código Penal Brasileiro, no seu artigo $75^{2}$.

Participante do programa de Remição pela Leitura, C.L. afirma que a leitura é uma libertação interior, em consonância com as ideias de Iser (1996) de que a realidade pode se transformar em ficção, sendo possível experimentar uma espécie de intervalo temporal na rotina carcerária. E, nesse momento de transição, é permitido a este leitor comparar a sua vida à dos

\footnotetext{
${ }^{2}$ Recentemente, foi alterado o art. 75, do decreto-lei 2.848/40 (Código Penal Brasileiro), pela Lei 13.964/19, que aumentou em 10 (dez) anos o tempo máximo de cumprimento de pena, totalizando 40 (quarenta) anos.
} 
heróis dos romances, e cita, como exemplo, Raskólhnikov, personagem principal da obra Crime e Castigo, que sofria tanto, e sua prisão era sua consciência, acabou por denunciar a si próprio.

C.L. diz ter lido oito livros e, com isso, conseguiu remir, aproximadamente, 30 dias de sua pena. Segundo seus cálculos, poderá diminuir dos seus 15 anos restantes de pena dois anos, se continuar no projeto. Para isso, já contabilizou: terá que ler mais 182 obras, rompendo as expectativas de alienação e modulação de comportamento existentes no confinamento. Nesse processo, revela ter feito uma descoberta: gostaria de se tornar escritor e escrever um livro sobre sua vida. Assim, reformulando a sua visão de mundo, segundo C.L., ele poderia impedir muitas pessoas de cometer erros.

Na segunda entrevista, o leitor é A.S., preso por roubo e formação de quadrilha, preso há 10 anos, revelou que "a leitura me ajuda a acumular conhecimentos, e aqui na prisão nós temos bastante tempo", denotando a ideia da funcionalidade da prática literária e da ociosidade na prisão, reafirmando a falha na proposta de ressocialização. Mesmo não sendo uma leitura espontânea, o leitor é enfático: "é muito bom e uma experiência totalmente nova". Diz gostar muito de trilogias, porque, segundo ele, "obrigam a ser paciente" e para ele, "isso também é novo". E, além disso, ainda, afirmou que a literatura estimula "a minha imaginação e abre a minha mente para novas ideias", por meio do imaginário proporciona a reformulação de mundo (ISER, 1996; JAUSS, 1994).

$\mathrm{Na}$ terceira entrevista, L.F., preso por crime hediondo, vê na leitura a possibilidade de se beneficiar dos dias da remição. Por isso, talvez, ao longo da reportagem, em uma das oficinas apresentadas, L.F. solicite ao diretor da penitenciária mais leitura, visto que, ao longo de 18 meses, só conseguiu ler 08 obras quando deveria ter realizado a leitura de 18 obras. Para L.F., a leitura abre seus horizontes no que se refere à ampliação das suas experiências e revela que o sofrimento o modifica. Ao final, desabafa, “depois de 10 anos preso, você não é mais a mesma pessoa, dez anos presos fazem muita diferença (sic)", possivelmente, esse tempo transcorreu sem atividades, sem remição, em completa ociosidade, marcas do encarceramento no Brasil. Considerando este viés, a leitura, como política pública para remição de pena, surge como um oásis em meio ao deserto.

Quando perguntados sobre o aprendizado das leituras realizadas e se isso poderia influenciar no processo de ressocialização, um dos internos entrevistado revelou que, ao refletir sobre a obra, entendeu que tomou decisões impensadas, somente com a intenção "de inflar o ego", de ganhar um dinheiro fácil ou por ganância. Contudo, se pensasse um pouco mais, poderia recomeçar, pensar nas pessoas que estão próximas, pois "elas que perdem, que sofrem 
as consequências" e, ao final, desabafa: "sou ladrão, traficante de drogas, e é toda a minha família que sofre as consequências (sic)".

No SPF, é proibida a comunicação entre celas, inclusive proibida a discussão sobre livros, em função de mecanismos de controle e de segurança. Em sua entrevista, a Coordenadora Geral do Tratamento Penitenciário acredita que, por meio da literatura, eles mantêm um contato com o exterior e alargam seus horizontes, além de observar uma mudança significativa no comportamento destes leitores durante o período de detenção.

Muitas vezes, a leitura é vista como um compromisso, evidenciado pela responsabilidade de se produzir um texto. No universo da prisão, não são dadas atribuições a estes sujeitos, não existem compromissos, tampouco responsabilidades, visto que sua proposta é modular comportamentos. Para Foucault (1997), a intervenção punitiva buscava no quadriculamento do corpo ou princípio da localização imediata do indivíduo no espaço, como possibilidade de aperfeiçoamento desse corpo até chegar ao estágio de um corpo dócil e útil. Nesse sentido, na prisão, o corpo era alvo do poder nos seus gestos, movimentos, atitudes. Portanto, esses controles minuciosos sobre operações e métodos de sujeição conduziriam a um sujeito pronto, transformado (FOUCAULT, 1997).

A leitura, também, é percebida como exercício de alteridade, pois dá ao leitor a possibilidade de se colocar no lugar do personagem, liberando em si a vontade de escrever, contar sua história, dar testemunho de sua experiência. Nos debates contemporâneos, o conceito de testemunho encontra-se associado ao trauma, um dos conceitos-chave da psicanálise, em uma representação metafórica de ferida na memória. A dor e o sofrimento podem ser transpostos para a realidade do cotidiano e se encontram materializados, também, no ato de escrever. Para Freud (apud SELLIGMAN-SILVA, 2003), os eventos da linguagem e seus testemunhos apresentam-se como uma modalidade de realização da verdade, não se tratando apenas de um enunciado, mas da possibilidade de acesso àquela verdade.

No primeiro depoimento, C.L. narra os efeitos estéticos da obra Crime e Castigo e do poder da leitura em tocar o indivíduo, ao ponto de levá-lo a se perceber no mundo e, a partir daí, renovar a sua percepção sobre o mundo. É esta nova percepção que o faz desejar ser um escritor para que possa libertar outros leitores do sentimento de culpa, assim como a leitura agiu sobre ele. Em resumo, o leitor apropria-se da ideia presente na obra de que a prisão é a sua própria consciência, como descreve Dostoiévski em sua narrativa e se liberta, atuando sobre a sua história (ISER, 1996). 
Merece destaque a reflexão de L.F., presente no último depoimento, que dá conta da importância da leitura na abertura de horizontes, conforme as teses postuladas por Jauss (1994), ao mesmo tempo em que este leitor deixa em evidência o impacto e o sofrimento causado pela pena: “depois de 10 anos preso, você não é mais a mesma pessoa, dez anos presos fazem muita diferença. (sic)". Embora a leitura represente este novo olhar sobre uma dada realidade, são fortes, ainda, as marcas do encarceramento: "sou ladrão, traficante de drogas". Seguramente, a leitura promoveu esta interação consigo mesmo, o que levou este leitor a refletir sobre a culpa que acabou por alcançar toda a sua família. Na prisão, esse leitor sofre os efeitos estéticos do texto e tem sua vida impactada pela possibilidade de rompimento das rotinas moduladoras de comportamento e da sua desprogramação no cárcere.

Em suma, os textos trazem em comum a ideia de uma intersecção entre o mundo da prisão e o mundo do texto, a partir das reflexões suscitadas e, sobretudo, percebidas nos depoimentos sobre a leitura da obra Crime e Castigo, estabelecendo um processo de reformulação de si mesmo (JAUSS, 1979; ISER, 1996). Por outro lado, quando conectado ao mundo do texto, indiretamente, parece que este leitor se sente vivo, como na sociedade extramuros, dada a possibilidade de conexão e de acesso ao livro, ainda que restrito e, de forma controlada, por meio do projeto de remição pela leitura. Dessa maneira, podemos afirmar que o ato de leitura humaniza esse sujeito que, embora, encarcerado, se sente um pouco mais gente, ser humano, e não apenas um criminoso.

\section{Considerações finais}

A proposta desta exposição de recortes dos textos resenhados pelos participantes do projeto e das entrevistas foi dar voz a estes leitores que, com pedidos de desculpas pelos erros ortográficos ou em uma atitude de agradecimento, tem tanto a contar, a compartilhar, mas, em raros momentos, o fazem. A impressão que se tem é como se, em alguns momentos de seus textos, enviassem uma carta a alguém distante, embora nunca obtivessem resposta.

Compartilhar suas histórias é revelar a outra face do processo de bonificação dos dias remidos pela leitura. Na realidade, é desvelar o comportamento destes leitores, demonstrando o aspecto subjetivo de todo o processo. Quase como o próprio nascimento, a escrita, nestes textos, revela-se libertadora. A importância da escrita para este sujeito encarcerado se revela como um grito de liberdade imbricado na palavra. Percebe-se que a convergência destas experiências - escrita e leitura - se dá de maneira imediata, no estímulo à produção de sua 
própria história, agora, sobre outra perspectiva, que não a mais conhecida socialmente, muitas vezes, em narrativas midiáticas ou televisivas, mas para dar testemunho de sua experiência.

Entretanto, percebe-se que a compreensão das leituras, de certa forma, está comprometida, já que não existem espaços para discussão do texto e compartilhamento das leituras. Percebe-se tal fato nos pedidos constantes de desculpas pelos erros ortográficos, pela incapacidade de compreensão do gênero resenha e, sobretudo, quando assumem não entenderem o texto a ser resenhado. Ainda, é perceptível a ausência de diálogos em todo o processo, já que sabem que não obterão respostas quanto às suas dúvidas.

Por fim, compreendemos que, no RDD, assim como em outros espaços de confinamento, a leitura tem várias facetas. Cumpre sua função utilitária, estando estreitamente vinculada à ideia de escolarização do conhecimento e de aprimoramento intelectual. Neste aspecto, acredito que mais pesquisas científicas nesses espaços dariam maior sustentação teórica para o desenvolvimento destas práticas de leitura e reavalização de políticas públicas.

Olhando mais de perto os impactos da leitura sobre o universo destes sujeitos, corroborado por meio de suas falas e textos, compreendemos que nesta sociedade disciplinar e moduladora de comportamentos, a leitura pode romper os efeitos da prisionização, se considerarmos os efeitos estéticos do texto e sua possibilidade de reformulação da sua visão de mundo, ressignificando sua existência. Ao promover a desalienação deste sujeito e abrir a porta que o reprograma para a vida, é possível, então, pensar em uma via possível de reinserção social.

\section{Referências}

BRASIL. Lei n. 7.210, de 11 de julho de 1984. Institui a Lei de Execução Penal. Diário Oficial da União, Brasília, 13 jul. 1984. Disponível em: Acesso em: 20 fev. 2020.

BRASIL. Ministério da Justiça, Departamento Penitenciário Nacional, Sistema Penitenciário Federal. Portaria n. 276 de 20 de junho de 2012. Dados disponíveis e <https://www.cjf.jus.br/cjf/documentos/portaria_remissaopelaleitura.pdf/view>. Acesso em: 27 jan. 2012.

BARATTA, Alessandro. Ressocialização ou controle social: uma abordagem crítica da "reintegração social" do sentenciado. Universidade de Saarland, RFA, Alemanha Federal. Disponível em < http://www. eap. sp. gov. br/pdf/ressocializacao. pdf>. Acesso em: maio 2020.

BARTHES, Roland. O prazer do texto. Trad. Maria Margarida Barahona. Pref. Eduardo Prado Coelho. Lisboa: Ed. 70, 1983. 
BRASIL. Ministério da Justiça, Departamento Penitenciário Nacional, Sistema Penitenciário Federal. I Anuário do Sistema Penitenciário Federal, 2015.

CÂNDIDO, Antônio. Literatura e sociedade. São Paulo: Nacional, 2006.

CHIES, Luiz Antônio Bogo. A questão penitenciária. Tempo Social, v. 25, n. 1, p. 15- 36, 2013.

COMPAGNON, Antoine. O demônio da teoria. Belo Horizonte: UFMG, 2001.

DOSTOIÉVSKI, Fiódor. Crime e castigo. Editorial Presença, 2011.

FOUCAULT, Michel. Vigiar e punir. Nascimento da Prisão. Trad. Raquel Ramalhete. 23a Ed. Rio de Janeiro: Ed. Vozes, 1997.

GOFFMAN, E. Manicômios, Prisões e Conventos. São Paulo, Editora Perspectiva, 1990.

ISER, Wolfgang. O ato de leitura: uma teoria do efeito estético. São Paulo: Ed. 34, 1996.

JAUSS, Hans Robert. A estética da recepção: colocações gerais. In: LIMA, Luiz Costa. A literatura e o leitor. Rio de Janeiro: Paz e Terra, 2002.

JAUSS, Hans Robert. A história da literatura como provocação à teoria literária. Ed. Ática, 1994.

JAUSS, Hans Robert. O prazer estético e as experiências fundamentais da poiesis, aisthesis e katharsis. A literatura e o leitor: textos de estética da recepção. Rio de Janeiro: Paz e Terra, v. 16, p. 2-18, 1979.

JOHN, V. M. Palavras da salvação: as representações da leitura na prisão. 2004. 193 f. 2004. Tese de Doutorado. Dissertação (Mestrado em Educação) -Universidade Federal de Santa Catarina, Florianópolis.

JOUVE, Vincent. A leitura. São Paulo: Ed. Unesp, 2002.

LEMGRUBER, Julita. Prisões do Brasil. Um pacote de equívocos que gera e mantém o caos. IHU ON-LINE - Revista do Instituto Humanitas Unisinos, $n^{\circ}$ 471, ano XV, 31- 08-2015.

MARTHA, Alice Aurea Penteado. Leituras na prisão. Maringá: Eduem, 2011.

MASSI, Fernanda, NAKAGOME, Patrícia Trindade (Org.). Desumanização na literatura. São Paulo: Mé Parió Revolução, 2015.

RAMOS, Graciliano. Memórias do cárcere. Rio de Janeiro/São Paulo: Record, 2008.

RIBEIRO, Maria Luzineide P. da Costa. O mundo como prisão e a prisão no mundo: Graciliano Ramos e a formação do leitor em presídios do Distrito Federal. Dissertação (Mestrado em Literatura) - Instituto de Letras. Brasília: Universidade de Brasília, 2012. SARTRE, Jean Paul. O imaginário. Tradução de Duda Machado. São Paulo: Editora Ática, 1996. 
SELIGMANN-SILVA, Márcio (Org.). História, memória, literatura: o testemunho na Era das Catástrofes. Campinas: Editora da Unicamp, 2003.

ZALUAR, Alba. Integração perversa: pobreza e tráfico de drogas. FGV Editora, 2004

Recebido em: 22/05/2020

Aceito para publicação em: 18/08/2020 